\title{
Kinetics in a Double Antibody Radioimmunoassay (RIA): Diffussion Control
}

\author{
C. Olivas Arroyo ${ }^{1}$, J. L. Moreno Frigols ${ }^{2,3, *}$ \\ ${ }^{1}$ Servicio de Medicina Nuclear, Hospital La Fe, Valencia, Spain \\ ${ }^{2}$ Departamento de Química Física, Facultad de Farmacia, Universidad de Valencia, Valencia, 46100, Spain \\ ${ }^{3}$ Servicio de Medicina Nuclear, Hospital Clínico Universitario, Valencia, 46010, Spain \\ jose.1.moreno@uv.es
}

\begin{abstract}
Competitive protein binding radioimmunoassay (CPB-RIA) is a principal method for quantifying serum C Peptide concentration. The accuracy of this method is critically dependent on factors that influence the reaction between anti-C Peptide antibody (P) with 125I-C Peptide (M). We studied the influence of initial concentration of M, ionic strength, and viscosity on the reaction between $\mathrm{M}$ and $\mathrm{P}$. A kinetic model for the the reaction between. Such model adjusts satisfactorily to the results. Bi-exponential and irreversible kinetics is determined. The results of the viscosity analysis show clear negative influence on the direct reaction rate. The ionic strength shows scarce influence on equilibrium and negligible influence upon the rate constant, which suggests that the variation resulting from the effect of the glycerol addition is not due to the influence of the dielectric constant of the solutions used. The effect of temperature shows activation parameters similar to the viscous flow energy of water, which suggests that the reaction is diffusion-controlled. The value of $\Delta \mathrm{H}^{\circ}$ for the immucomplex formation is positive, as is the case with endothermic processes.
\end{abstract}

Keywords C Peptide, Antibody, Kinetics, Temperature, Viscosity, Ionic Strength, Diffusive Control

\section{Introduction}

C peptide is a polypeptide ( 31 amino acid residues) with a relative molecular mass (RMM) of 3018 Dalton. It is part of the proinsulin molecule and has the following structure: $\mathrm{B}$ chain - Arg - Arg -C-peptide - Lys - Arg - A chain.

In the pancreatic $\beta$-cells, proinsulin is enzymatically cleaved into insulin (A chain and B chain) and the C-peptide molecule. Both are simultaneously secreted in equimolar concentrations into blood. Insulin has a rather short half-life -5 minutes- while the half-life of $\mathrm{C}$ peptide is 30 minutes. Therefore, the molar ratio between $\mathrm{C}$ peptide and insulin in peripheral blood ranges between $3: 1$ and 5:1. The main degradation site for $\mathrm{C}$ peptide is the kidney. Consequently, patients with renal dysfunction have a longer half-life and higher basal values. Among other reasons, its determination is indicated in the study of pancreatic reserves in individuals with diabetes and pancreatectomy patients, and in insulinoma diagnosis.

Radioimmunoassay (RIA) is used in C Peptide assessment. It is a competitive technique in which the antigen molecule to be determined $(\mathrm{Ag})$ competes with a radioactive tracer (labelled antigen: $\mathrm{Ag}^{*}$ ) in order to bind to a specific antibody

* Corresponding author:

jose.1.moreno@uv.es (J. L. Moreno Frigols)

Published online at http://journal.sapub.org/chemistry

Copyright (C) 2012 Scientific \& Academic Publishing. All Rights Reserved
(Ab) that binds to both antigens until equilibrium is reached, in which circumstance both immunocomplexes -the radioactive one and the non-radioactive or "cold" one- can coexist :

$$
\mathrm{Ag}+\mathrm{Ab}+\mathrm{Ag}^{*} \leftrightarrow(\mathrm{Ag}-\mathrm{Ab})+(\mathrm{Ag}-\mathrm{Ab})^{*}
$$

By keeping tracer $\left(\mathrm{Ag}^{*}\right)$ and antibody $(\mathrm{Ab})$ quantities constant, the higher or lower proportion in the immunocomplexes formed will solely depend on the amount of cold antigen $(\mathrm{Ag})$ in the sample to be analysed.

If the tracer behaves similarly when bound or in solution, then the separation of the bound and free fractions is essential. In our case, separation is accomplished by fixation on a second antibody coated on a plastic bead.

Kinetics and equilibrium in antigen-antibody reactions are determining factors of the rapidity, analytical range, and reliability of immunoanalytical techniques. Likewise, the search for more reliable faster immunoassays is one of the main development areas in this field. This has caused the overall process to be progressively automated, from sample handling to statistical assessment of results. Yet, despite the large number of immunoanalytical systems developed in recent years, very few of them include kinetic analysis.

A diffusion-controlled process must meet some typical requirements such as a considerable reaction rate decrease when medium viscosity is greater, and scarce temperature influence with a reduced energy demand with regards activation, this causing activation enthalpy values to be the same order as the solvent's viscous flow energy $(5000 \mathrm{cal} / \mathrm{mol}$ for 
water). The influence of diffusion on the speed of the antigen-antibody reaction has been treated by several authors [1-7]. This paper focuses on the kinetics of the reactions between C Peptide and its specific antibodies. The target is to characterise radioimmunoanalytical reactions and in particular those used in C Peptide measurement, based on the following steps:

1- Obtaining integrated rate equations for the overall process.

2- Setting up the possible diffusion control through the study of temperature influence upon reaction kinetics

3- As a complementary factor, the influence of viscosity on such process is analysed, which requires it to be studied in media with different compositions.

4- The media have different dielectric constants which -should the reaction occur between charged species- would give way to an effect that would overlap with that of viscosity. In order to indirectly estimate this potential influence, reactions are studied in media with different ionic strength.

This study allows us to ascertain the following:

- The reversibility or irreversibility of the reaction.

- The presence of one or more types of binding sites[8-10]. In this case, it is not always possible to determine whether such binding sites are found together in the same antibody molecule or in different molecules.

\section{General Model}

Symbols: $\mathrm{P}=$ antibody in solution, $\mathrm{M}={ }^{125}$ Iodine-labelled antigen (C Peptide), $\mathrm{J}=$ second antibody coated on plastic beads, $\mathrm{P}_{0}, \mathrm{M}_{0}=$ initial concentrations in arbitrary units, $\mathrm{PM}$, $\mathrm{PMJ}=$ radioactive immunocomplexes, $(\mathrm{P}),(\mathrm{M}),(\mathrm{PM}),(\mathrm{PMJ})$ $=$ concentrations in $\mathrm{mol} / \mathrm{L},(\mathrm{J})=$ concentration of vacant biding sites in antibody $\mathrm{J}, \mathrm{Z}=\mathrm{cpm}$ activity in each tube after reaction $\left(Z=Z_{s p}+Z_{0}\right)$ The tables include a sub-index indicating the experience number. $Z_{\mathrm{sp}}=\mathrm{cpm}$ activity from the radioactive immunocomplex, corresponds to specific binding. $Z_{0}=$ value of $Z$ at $t=0$, corresponds to non-specific binding, $Z_{\infty}=$ value of $Z$ obtained at $t$ infinity, $Z_{\mathrm{e}}=$ value of $Z$ at equilibrium $\left(Z_{\mathrm{e}}=Z_{\infty}-Z_{0}\right), t=$ time in minutes, $\mathrm{k}=$ rate constant, $\mathrm{K}=$ equilibrium constant, $\mathrm{r}=$ correlation coefficient

It can be assumed that the global reaction is:

$$
\begin{gathered}
\mathrm{k}_{\mathrm{D}} \\
\mathrm{P}+\mathrm{J}
\end{gathered}
$$

which can be explained by the following reaction mechanism:

$$
\begin{aligned}
& \mathrm{k}_{1} \\
\mathrm{P}+\mathrm{M} \leftrightarrow & \mathrm{P} \cdots \cdot \mathrm{M} \text { (Slow) } \\
& \mathrm{k}_{-1} \\
& \mathrm{k}_{2} \\
\mathrm{P} \cdots \cdot \mathrm{M} \leftrightarrow & \mathrm{PM} \text { (Quick) } \\
& \mathrm{k}_{-2} \\
& \mathrm{k}_{3} \\
\mathrm{PM}+\mathrm{J} \leftrightarrow & \mathrm{PMJ} \text { (Quick) } \\
& \mathrm{k}_{-3}
\end{aligned}
$$

where the first stage consists of the diffusion approxima- tion of the reacting molecules until the encounter complex $(\mathrm{P} \cdots \mathrm{M})$ is formed. It is deemed reversible, since the encounter complex can be dissociated, but this is not very likely due to the cell effect. At the second stage, the intermediate immunocomplex (PM) is formed, and the third stage sees the binding of the immunocomplex to the second antibody immobilised on a bead.

The rate equation previously deducted for the overall process[11], and applied to a system that does not contain unlabeled antigen $\left(\mathrm{Q}_{0}=0\right)$ is:

$$
\begin{aligned}
& \mathrm{Z}=\frac{\mathrm{P}_{01} \mathrm{M}_{0}}{\mathrm{M}_{0} \mathrm{~K}_{1}}\left[\begin{array}{llll}
1-\exp -t \mathrm{k}_{\mathrm{D} 1} \mathrm{M}_{0} & \mathrm{~K}_{1}
\end{array}\right] \\
& +\frac{\mathrm{P}_{02} \mathrm{M}_{0}}{\mathrm{M}_{0} \mathrm{~K}_{2}}\left[1-\exp -\mathrm{tk}_{\mathrm{D} 2} \mathrm{M}_{0} \mathrm{~K}_{2}\right] \mathrm{Z}_{0}
\end{aligned}
$$

Parameters $\mathrm{K}_{1}$ and $\mathrm{K}_{2}$ represent equilibrium constants. Likewise, $\mathrm{k}_{\mathrm{D} 1}$ and $\mathrm{k}_{\mathrm{D} 2}$ are rate constants.

In the equations that appear in results, the term $Z_{0}$ is taken as proportional to $\mathrm{M}_{0}$.

Equilibrium equations are obtained from rate equations by making time tend to infinity. By doing this, exponential terms containing such a variable disappear, and by subtracting the unspecific activity $\left(\mathrm{Z}_{\mathrm{e}}=\mathrm{Z}_{\infty}-\mathrm{Z}_{0}\right)$.

\section{Matherial and Methods}

\subsection{Reagents}

The reagents used belong to the RIA-coat ${ }^{\circledR}$ C-Peptid kit, manufactured by Byk-Sangtec Diagnostica GMBH \& Co.KG. The kit includes:

- A polyclonal antiserum obtained by immunising goats with synthetic human C-peptide

- A second monoclonal antibody (mouse anti goat) coated on a plastic bead

- ${ }^{125}$ I-C-peptide: a vial with lyophilised labelled C peptide

\subsection{Instrumentation}

LKB Gammamaster Automatic Gamma Counter, fitted with a computer with a Riacalc programme.

\subsection{Computer Programme}

Statistica (Copyright $(C)$ StatSoft, Inc.1993). It allows the fitting of experimental data using specific non-linear regression equations, and the production of the corresponding tables. As a statistical criterion for equation selection in the different models, AIC (Akaike's Information Criterion) was observed; it can be expressed as follows: $\mathrm{AIC}=\mathrm{N} \cdot \ln \mathrm{S}+2 \cdot \mathrm{P}$, where $\mathrm{N}$ is the number of points, $\mathrm{S}$ the addition of the squares of the residuals, and $\mathrm{P}$ the number of parameters in the equation. The equation with the lowest AIC in the fitting must be chosen. That equation only is indicated in Results.

\subsection{Experimental Procedure}

Tube series were prepared with $100 \mu \mathrm{L}$ of each of the different labelled antigen solutions, together with $100 \mu \mathrm{L}$ of antibody solution and a bead. They were left to react in agi- 
tation for different time periods, after which they were washed, eliminating the liquid and leaving the bead in order to measure its radioactivity on the counter. One tube from each series was left to react for 24 hours, this being considered infinite time and therefore corresponding to the value at equilibrium. The added total radioactivity was measured as an indirect measurement of the initial concentration of the labelled antigen. 48 experiences were performed, arranged as follows:

Experiences 1-16: Study of the influence of temperature upon reaction kinetics and equilibrium. In this case, four series were configured (one for each temperature) where 100 $\mu \mathrm{L}$ 125I-C Peptide was left to react until the corresponding time was reached.

Experiences 17-32: Study of the influence of viscosity; this required each tube to be added $100 \mu \mathrm{L}$ of the different 125I-C Peptide solutions prepared with glycerol.

Experiences 33-48: The procedure followed in the viscosity study was also observed in the ionic strength influence analysis, but labelled C Peptide solutions were prepared with sodium chloride.

\section{Results and Discussion}

\subsection{Influence of Temperature (T) and Labeled C Peptide Initial Concentration $\left(M_{0}\right)$ on Reaction Kinetics and Equilibrium}

This was studied in experiments 1-16; their results can be seen in Table 1.

Table 1 shows that, for a given $\mathrm{M}$ value, if $\mathrm{T}$ increases, the amount of radioactive immunocomplex also increases for all times, except for values of $t=\infty$. The data in Table 1 have been fitted to Eq 2. This equation is obtained from Eq 1 by expressing $\mathrm{K}_{1}$ and $\mathrm{K}^{2}$ parameters trhoug the van t'Hoff equation, and the $\mathrm{k}_{01}$ and $\mathrm{k}_{02}$ trhoug Eyring's. Parameters $\mathrm{c}$ and $f$ include the ratios of enthalpy and the constant $R$.

$$
\begin{aligned}
& z=\frac{P_{01} M_{0}}{M_{0} C_{1} \exp \frac{-c_{1}}{T}}\left[1-\exp -t F_{1} T \exp \frac{-f_{1}}{T}\left[M_{0} C_{1} \exp \frac{-c_{1}}{T}\right]\right] \\
& \frac{P_{02} M_{0}}{M_{0} C_{2} \exp \frac{-c_{2}}{T}}\left[1-\exp -t F_{2} T \exp \frac{-f_{2}}{T}\left[M_{0} C_{2} \exp \frac{-c_{2}}{T}\right]\right] \\
& p M_{0}
\end{aligned}
$$

These are its parameters and coefficient:

$$
\begin{array}{ccccc}
\mathrm{P}=30170 & \mathrm{C}_{1}=18145 & \mathrm{c}_{1}=-712 & \mathrm{~F}_{1} \cdot 10^{4}=1915 & \mathrm{f}_{1}=1915 \\
\mathrm{P}_{02}=185580 & \mathrm{C}_{2}=126335 & \mathrm{c}_{2}=-192,6 & \mathrm{~F}_{2} \cdot 10^{6}=0,012 & \mathrm{f}_{2}=2114 \\
\mathrm{p}=0,000598 & \mathrm{r}=0,997 & \mathrm{AIC}=1788 & &
\end{array}
$$

Eq 2 shows that, by increasing the temperature, the apparent rate constants and the dissociation equilibrium constants are increased. From parameters $c_{1}, c_{2}, f_{1}$ and $f_{2}$ in the equation, values can be obtained for the dissociation reaction enthalpies: $\Delta \mathrm{H}^{0}{ }_{1}=-1424 \mathrm{cal} \cdot \mathrm{mol}^{-1}$ and $\Delta \mathrm{H}^{0}{ }_{2}=-385.2 \mathrm{cal} \cdot \mathrm{mol}^{-1}$, and for the activation enthalpies: $\Delta \mathrm{H}^{*}=3830 \mathrm{cal} \cdot \mathrm{mol}^{-1}$ and $\Delta \mathrm{H}_{2}^{\ddagger}=4228 \mathrm{cal} \cdot \mathrm{mol}^{-1}$ respectively. Since dissociation en- thalpies are negative, formation ones will be positive, as is the case with endothermic processes. Activation enthalpies

\begin{tabular}{|c|c|c|c|c|c|c|c|c|c|}
\hline & \multicolumn{7}{|c|}{$\mathrm{t}(\mathrm{min})$} & \multirow{2}{*}{$\begin{array}{l}\mathrm{M}_{0} \\
\text { (cpr@) }\end{array}$} & \multirow{2}{*}{$\begin{array}{c}\mathrm{T} \\
(\mathrm{K})\end{array}$} \\
\hline & 0 & 10 & 30 & 60 & 90 & 120 & $\infty$ & & \\
\hline$Z_{1}$ & 129 & 688 & 1740 & 2817 & 4264 & 5601 & 13018 & 16274 & 278 \\
\hline $\mathrm{Z}_{2}$ & 0 & 453 & 1217 & 129 & 688 & 4339 & 9544 & 12590 & 278 \\
\hline$Z_{33}$ & 33 & 340 & 856 & 0 & 453 & 2400 & 6310 & 8305 & 278 \\
\hline $\mathrm{Z}_{4}{ }_{44}$ & 0 & 121 & 416 & 73 & 929 & 1231 & 2983 & 3739 & 278 \\
\hline $\mathrm{Z}_{55}$ & 129 & 759 & 1859 & 3802 & 5524 & 7382 & 14445 & 16274 & 286 \\
\hline $\mathrm{Z}_{6}{ }_{66}$ & 0 & 489 & 1526 & 2956 & 4237 & 5704 & 10399 & 12590 & 286 \\
\hline $\mathrm{Z}_{7}{ }_{77}$ & 33 & 376 & 1003 & 1793 & 2630 & 3551 & 6928 & 8305 & 286 \\
\hline $\mathrm{Z}_{8}$ & 0 & 104 & 518 & 870 & 1326 & 1573 & 3108 & 3739 & 286 \\
\hline $\mathrm{Z}_{9}{ }_{99}$ & 129 & 840 & 2504 & 3810 & 6304 & 8089 & 14055 & 16274 & 291 \\
\hline $\mathrm{Z}_{10}{ }_{100}$ & 0 & 652 & 1944 & 3274 & 4822 & 6055 & 10602 & 12590 & 291 \\
\hline $\mathrm{Z}_{11}$ & 33 & 479 & 1370 & 1949 & 2806 & 3714 & 7333 & 8305 & 291 \\
\hline$Z_{12}{ }_{1212}$ & 0 & 175 & 629 & 974 & 1349 & 1692 & 3233 & 3739 & 291 \\
\hline$Z_{13}{ }_{1313}$ & 129 & 1079 & 3041 & 5242 & 6997 & 8352 & 13687 & 16274 & 301 \\
\hline $\mathrm{Z}_{14}{ }_{1414}$ & 0 & 771 & 2220 & 4228 & 5266 & 6346 & 10625 & 12590 & 301 \\
\hline $\mathrm{Z}_{15}{ }_{1515}$ & 33 & 506 & 1216 & 2440 & 3408 & 4126 & 6998 & 8305 & 301 \\
\hline${ }_{616}^{Z_{16}}$ & 0 & 189 & 675 & 1183 & 1666 & 2007 & 3332 & 3739 & 301 \\
\hline
\end{tabular}
have the same magnitude order as the viscous flow energy of water, this being a feature of diffusion-controlled processes.

The consistency between the observed values (Table 1) and those calculated by Eq. 2 is shown in figure 1.

Table 1. Influence of $\mathrm{T}$ and $\mathrm{M}_{0}$

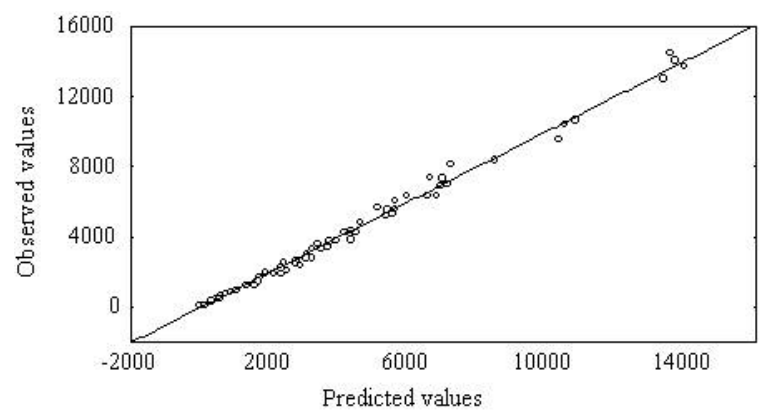

Figure 1. Observed values (Table 1) vs. Predicted values (Eq 2). Observed values $=-44.09+1.0054 \cdot$ Predicted values, $r=0.997$

$$
\begin{gathered}
\mathrm{Z}_{0}=\frac{30170 \mathrm{M}_{0}}{\mathrm{M}_{0} \quad 18145 \exp \frac{712}{\mathrm{~T}}} \frac{185580 \mathrm{M}_{0}}{(\mathrm{r}=0,995)} \\
\mathrm{M}_{0} \quad 126335 \exp \frac{192,6}{\mathrm{~T}}
\end{gathered}
$$

Equilibrium results at infinite time are fitted to Eq. $5 \mathrm{~b}$, 
obtained by making $t$ tend to infinity in Eq 3

\subsection{Influence of Viscosity ( $\eta$ ) and Labeled C Peptide Initial Concentration $\left(\mathrm{M}_{0}\right)$ on Reaction Kinetics and Equilibrium}

This was studied in experiments 17-32; their results can be seen in Table 2.

Table 2. Influence of $\eta$ and $M 0$

\begin{tabular}{|c|c|c|c|c|c|c|c|c|}
\hline & \multicolumn{6}{|c|}{$\mathrm{t}(\mathrm{min})$} & \multirow{2}{*}{$\begin{array}{c}\mathrm{M}_{0} \\
(\mathrm{cpm})\end{array}$} & \multirow{2}{*}{$\begin{array}{c}\eta \\
(\mathrm{mPa} \cdot \mathrm{s})\end{array}$} \\
\hline & 0 & 20 & 40 & 80 & 120 & $\infty$ & & \\
\hline $\mathrm{Z} 17$ & 393 & 680 & 1054 & 2095 & 2850 & 6378 & 8078 & 1,37 \\
\hline Z18 & 214 & 385 & 1399 & 2258 & 2315 & 5090 & 6550 & 1,37 \\
\hline Z19 & 174 & 350 & 773 & 1293 & 1414 & 3050 & 4726 & 1,37 \\
\hline $\mathrm{Z} 20$ & 506 & 642 & 622 & 968 & 975 & 1904 & 2613 & 1,37 \\
\hline $\mathrm{Z} 21$ & 247 & 457 & 769 & 1706 & 2882 & 6346 & 8078 & 1,41 \\
\hline Z22 & 305 & 480 & 776 & 1429 & 3093 & 4937 & 6550 & 1,41 \\
\hline Z23 & 127 & 243 & 927 & 1457 & 1535 & 3174 & 4726 & 1,41 \\
\hline Z24 & 173 & 257 & 469 & 795 & 902 & 1902 & 2613 & 1,41 \\
\hline $\mathrm{Z} 25$ & 592 & 748 & 9330 & 1590 & 2042 & 6065 & 8078 & 1,51 \\
\hline Z26 & 241 & 390 & 651 & 1229 & 2157 & 5378 & 6550 & 1,51 \\
\hline $\mathrm{Z} 27$ & 299 & 404 & 498 & 991 & 1393 & 3561 & 4726 & 1,51 \\
\hline Z28 & 120 & 195 & 753 & 999 & 965 & 2164 & 2613 & 1,51 \\
\hline Z29 & 200 & 341 & 757 & 1568 & 1884 & 6009 & 8078 & 1,62 \\
\hline $\mathrm{Z} 30$ & 570 & 663 & 705 & 1233 & 1589 & 4410 & 6550 & 1,62 \\
\hline Z31 & 235 & 336 & 411 & 845 & 1599 & 3719 & 4726 & 1,62 \\
\hline $\mathrm{Z} 32$ & 292 & 356 & 319 & 609 & 840 & 2082 & 2613 & 1,62 \\
\hline
\end{tabular}

Table 2 shows that, for a given $M$ value, if viscosity increases, the amount of radioactive immunocomplex decreases for all times. This could be put down to a lag in the approximation stage of the reacting species. The data in the table are fitted to Eq 4.

$$
Z=\mathrm{aM}_{0}\left[1-\exp -\mathrm{tk}_{\mathrm{D}_{1}}^{\prime}\right] \mathrm{f}_{0}\left[1-\exp -\mathrm{t} \frac{\mathrm{k}_{\mathrm{D}_{2}}^{\prime}}{\mathrm{e}^{\prime}}\right] \mathrm{p}^{\prime} \mathrm{M}_{0}
$$

Equation 4 is obtained from Eq 1 by expressing $\mathrm{k}_{01}$ and $\mathrm{k}_{02}$ parameters trhoug the Kramers equation[12] and simplifying.

Its parameters and coefficients are as follows:

$$
\begin{array}{rrrr}
\mathrm{a}=0,425 & \mathrm{k}_{\mathrm{D} 1}^{\prime}=0,00388 & \mathrm{f}=0,306 & \mathrm{k}_{\mathrm{D} 2}^{\prime}=0,00062 \\
\mathrm{e}^{\prime}=-1,270 & \mathrm{p}^{\prime}=0,033 & \mathrm{r}=0,990 & \mathrm{AIC}=1478
\end{array}
$$

In the equation, viscosity reduces the direct reaction rate, initially determined by the equation 5 :

$$
\mathrm{v}_{\mathrm{D} 0}=\frac{\mathrm{dZ}}{\mathrm{dt}}=\mathrm{aM}_{0} \mathrm{k}_{\mathrm{D} 1} \frac{\mathrm{fm}_{0} \mathrm{k}_{\mathrm{D}_{2}}}{\mathrm{e}^{\prime}}
$$

The decrease only affects one of the binding site.

The consistency between the observed values (Table 2) and those calculated by Eq 4 is shown in Figure 2.

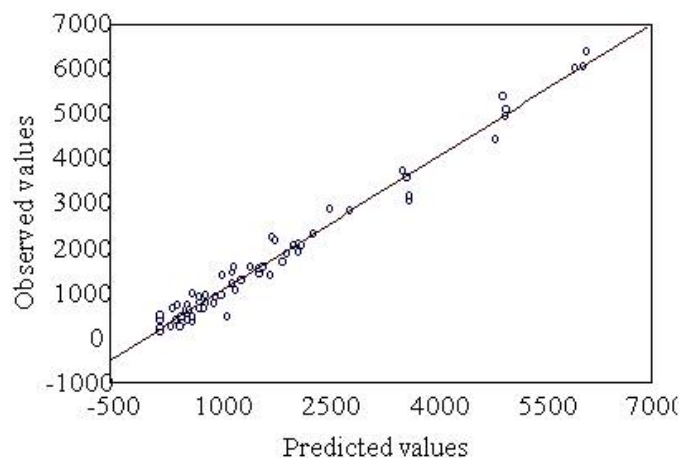

Figure 2. Observed values (Table 2) vs. Predicted values (Eq 4). Observed values $=48.605+0.98391 \cdot$ Predicted values, $r=0.990$

Equilibrium results at infinite time are fitted to $\mathrm{Eq} 6$ otained by making $t$ tend to infinity in Eq 5

$$
\mathrm{Ze}=0,731 \cdot \mathrm{M}_{0} \quad(\mathrm{r}=0,986)
$$

The defective fitting obtained could be caused by the reaction not reaching equilibrium under the experimental conditions, due to the greater slowness at which it is produced as a consequence of the increased viscosity.

\subsection{Influence of Ionic Strength (I) and Labeled C Pep- tide Initial Concentration $\left(M_{0}\right)$ on Reaction Kinetics

\begin{tabular}{|c|c|c|c|c|c|c|c|c|}
\hline & \multicolumn{6}{|c|}{$\mathrm{t}(\min )$} & \multirow{2}{*}{$\begin{array}{c}\mathrm{M}_{0} \\
(\mathrm{cpm})\end{array}$} & \multirow{2}{*}{$\begin{array}{c}\mathrm{I} \\
(\mathrm{mol} / \mathrm{L})\end{array}$} \\
\hline & 0 & 20 & 40 & 80 & 120 & $\infty$ & & \\
\hline Z33 & 555 & 2205 & 3138 & 4858 & 5996 & 7610 & 8911 & 0,053 \\
\hline Z34 & 347 & 1612 & 3020 & 4133 & 4764 & 6107 & 6689 & 0,053 \\
\hline Z35 & 264 & 1232 & 2143 & 2863 & 3333 & 3935 & 4625 & 0,053 \\
\hline Z36 & 198 & 733 & 1527 & 2046 & 1912 & 2661 & 2919 & 0,053 \\
\hline Z37 & 535 & 2022 & 3253 & 4747 & 5578 & 8213 & 8911 & 0,105 \\
\hline Z38 & 561 & 1695 & 2647 & 3847 & 4768 & 6018 & 6689 & 0,105 \\
\hline Z39 & 158 & 1146 & 2033 & 2697 & 3473 & 4668 & 4625 & 0,105 \\
\hline $\mathrm{Z} 40$ & 256 & 833 & 1335 & 1789 & 2026 & 2523 & 2919 & 0,105 \\
\hline Z41 & 444 & 2194 & 3615 & 5270 & 5715 & 7655 & 8911 & 0,158 \\
\hline Z42 & 382 & 1768 & 2495 & 3615 & 4351 & 6397 & 6689 & 0,158 \\
\hline Z43 & 409 & 1364 & 1855 & 2664 & 3262 & 4406 & 4625 & 0,158 \\
\hline Z44 & 203 & 637 & 868 & 1238 & 1577 & 2122 & 2919 & 0,158 \\
\hline Z45 & 539 & 1924 & 3116 & 4507 & 5456 & 7571 & 8911 & 0,211 \\
\hline Z46 & 376 & 1477 & 2635 & 3569 & 4048 & 6075 & 6689 & 0,211 \\
\hline Z47 & 374 & 1121 & 1602 & 2483 & 2967 & 4243 & 4625 & 0,211 \\
\hline Z48 & 317 & 858 & 1001 & 1685 & 1892 & 2833 & 2919 & 0,211 \\
\hline
\end{tabular} and Equilibrium}

This was studied in experiments 33-48; their results can be seen in Table 3.

Table 3. Influence of I and M0

As can be seen in Table 3, the influence of the ionic 
strength is little relevant, since -at increased values- the immunocomplex amount does not display a definite trend. The table data are fitted to Eq 7.

$$
\begin{aligned}
& Z=\frac{\mathrm{aM}_{0}}{\exp -\mathrm{u}^{\prime} \mathrm{I}^{0,5}}\left[1-\exp -\mathrm{tk}_{\mathrm{D} 1}^{\prime}\right] \\
& \frac{\mathrm{f} \mathrm{M}_{0}}{\exp -\mathrm{w}^{\prime} \mathrm{I}^{0,5}}\left[1-\exp -\mathrm{tk}_{\mathrm{D} 2}^{\prime}\right] \mathrm{p}^{\prime} \mathrm{M}_{0}
\end{aligned}
$$

Equation 7 is obtained from Eq 1 by expressing $\mathrm{k} 01$ and k02 parameters trhoug the Debye-Hückel equation[13] .

Its parameters and coefficients are:

$$
\begin{array}{cccc}
\mathrm{a}=0,801 & \mathrm{u}=-0,544 & \mathrm{k}_{\mathrm{DI}}^{\prime}=0,01590 & \mathrm{f}=0,0967 \\
\mathrm{~W}=2,04 & \mathrm{k}^{\prime} \mathrm{D} 2=0,00173 & \mathrm{P}=0,0597 & \mathrm{R}=0,995
\end{array}
$$$$
\mathrm{AIC}=1469
$$

The effect of the ionic strength suggests that the reacting species are electrically charged, even though such influence is negligible and only seen in equilibrium parameters. The product of the charges obtained from $\mathrm{u}^{\prime}$ annd $\mathrm{w}^{\prime}$ parameters is -0.232 for one of the binding sites and 0.870 for the other, which indicates that the reacting species are of a different sign for the first one and of the same sign for the second one.

The consistency between the observed values (Table 3) and those calculated by Eq 7 is shown in Figure 3.

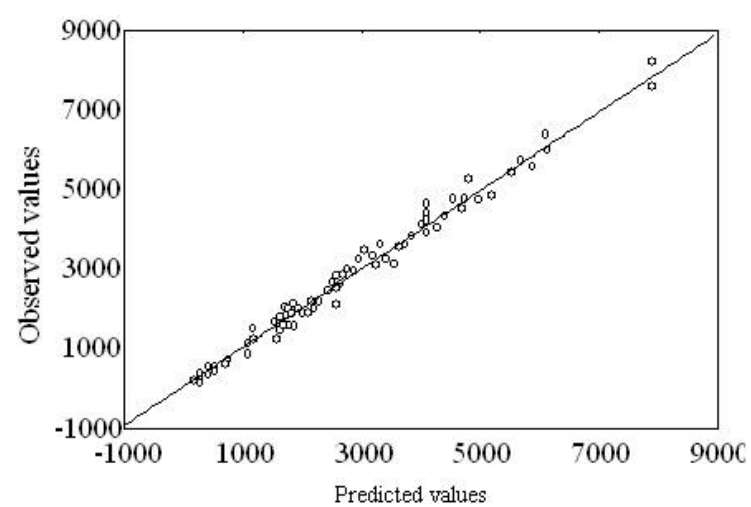

Figure 3. Observed values (Table 3) vs. Predicted values (Eq 7). Observed values $=63.034+0.98493 \cdot$ Predicted values, $r=0.995$

The results at infinite time, corresponding to the equilibrium, fits to the Eq 8, obtained by making $t$ tend to infinity in Eq 7.

$$
Z_{\mathrm{e}}=\frac{0,801 \mathrm{M}_{0}}{\exp 0,544 \mathrm{I}^{0,5}} \frac{0,0967 \mathrm{M}_{0}}{\exp -2,04 \mathrm{I}^{0,5}} \mathrm{r}=0,990
$$

\section{Conclusions}

1. An apparently irreversible biexponential behaviour is found, corresponding to the binding with two binding site types.

2. Temperature influence is in line with the behaviour foreseen by Eyring and van t'Hoff equations. Activation enthalpies: $\Delta \mathrm{H}_{1}^{\dagger}=3830 \mathrm{cal} \cdot \mathrm{mol}^{-1}$ and $\Delta \mathrm{H}_{2}{ }^{\dagger}=4228 \mathrm{cal} \cdot \mathrm{mol}^{-1}$, and disociation enthalpies: $\Delta \mathrm{H}_{1}{ }^{0}=-1424 \mathrm{cal} \cdot \mathrm{mol}^{-1}$ and $\Delta \mathrm{H}_{2}{ }^{0}$ $=-385.2 \mathrm{cal} \cdot \mathrm{mol}^{-1}$. Since dissociation enthalpies are negative, formation ones will be positive, as is the case with endothermic processes.

3. As to viscosity influence, viscosity causes the immunocomplex amount to decrease for all times. This is ex- plained by the lag in the approximation stage of the reacting species. Equilibrium is not affected.

4. Ionic strength influence is in line with the behaviour determined by the Debye-Hückel equation. The effects of the increased ionic strength on the apparent rate constants are negligible, while the effects on the dissociation equilibrium constants lead to an increase in the first one and a decrease in the second one. The value of the product of the charges $\left(z_{1} \cdot z_{2}\right)$ for the first binding site is -0.232 and 0.870 for the second one.

5. Since the effect of the ionic strength is negligible, kinetic variations due to the different glycerol concentrations used do not seem to result from the influence of the dielectric constants of such solutions, and so they could be due to viscosity only.

6. The above conclusions, together with the fact that the activation enthalpies obtained are of the same magnitude order as the viscous flow energy of water $\left(\approx 5000 \mathrm{cal} \mathrm{mol}^{-1}\right)$ point to diffusion control for these processes.

7. Equilibrium data do not allow us to discriminate between one and two binding site models. However, discrimination between both models is possible using kinetic data.

\section{REFERENCES}

[1] Nygren, H., Werthen, M. and Stenberg, 1988, Kinetics of antibody binding to solid-phase-immobilised antigen. Effect of diffusion rate limitation and steric interaction. Journal of Immunological Methods., 101, 63-71.

[2] Nygren, H. and Stenberg, M., 1989, Immunochemistry at interfaces. Immunology, 66, 321-327.

[3] Stenberg, M. and Stiblert, L., 1986, External diffusion in Solid-Phase Immunoassays. J. Theor. Biol., 120, 129-140.

[4] Stenberg, M. and Nygren, H., 1988, Kinetics of antigen-antibody reactions at solid-liquid interfaces. J. Inmunol. Methods., 113, 3-15.

[5] Stenberg, M., Werthen, .M, Theander, S. and Nygren, H., A diffusion limited reaction theory for a microtiter plate assay Journal of Immunological Methods, 112, 23-29.

[6] Raman, C.S. et al, 1992, Diffusion-limited rates for monoclonal antibody binding to cytochrome c, Biochemistry 31(42), 10370-9.

[7] Xavier, K. and Willson, R. C., 1998, Association and Dissociation Kinetics of Anti-Hen Egg Lysozime Monoclonal Antibodies HyHEL-5 and HyHEL-10, Biophysical Journal, 74, $2036-2045$

[8] Weber, G., The binding of small molecules to proteines, in: Molecular Biophysics, eds. B. Pullman and M.Weissblut (Academic Press, New York) p. 369

[9] Motulsky, H.J.and Mahan, L., 1984, The kinetics of competitive radioligand binding predicted by the law of mass action. Mol.Pharmacol., 25,1.

[10] Karlsson, M. Neil A., 1988, Estimation of binding parameters by kinetic data analysis: Differentiation between one and two binding sites. Eur. J. of Pharm., 148, 115-125. 
[11] Kusnezow, W., Syagailo, Y.V., Rüffer, S., Klenin, K., Sebald,W., Hoheisell, J.D. et al, 2006, Kinetics of anti gen binding to antibody microspots: Strong limitation by mass transport to the surface. Proteomics, 6, 794- 803

[12] McCammon JA, 2009, Darwinian biophysics: Electrostatics and evolution in the kinetics of molecular binding. Proc Natl Acad Sci USA, 106:7683-7684.

[13] McCammon, J.A., 2011, Gated Diffusion-controlled Reactions, BMC Biophysics, 4 (4)
[14] Olivas, C., Duart, M.J..Moreno, J.L., 2002, J Immunoassay \& Immunochemistry, 23 (4), 407- 428.

[15] Kramers, H.A., 1940, Brownian motion in a field of force and the diffusion model of chemical reactions. Physica, 7 , 284-304).

[16] Atkins, P.W. "Physical Chemistry".Oxford University Press (1983). 